\title{
Asymmetric Competition in B2B Spot Markets
}

\author{
Hila Etzion \\ Ross School of Business, University of Michigan, Ann Arbor, Michigan 48109, etzionh@bus.umich.edu \\ Edieal J. Pinker \\ Simon Graduate School of Business, University of Rochester, Rochester, New York 14627, \\ ed.pinker@simon.rochester.edu
}

\begin{abstract}
$W^{e}$ e model strategic behavior of two types of suppliers in B2B spot markets: a supplier that has forward contracts and uses the spot market only for inventory liquidation, and a supplier that uses the spot market as its sole selling channel. We find that when the spot market demand is small, the supplier that has forward contracts has a higher incentive to invest in expanding the spot market. When the spot market demand exceeds a threshold size, this situation is reversed, and the supplier with no contracts benefits more from making the spot market more prevalent. We show that a supplier with forward contracts benefits from the existence of the spot market more than a supplier with no contracts and that this result holds with both negative and positive correlation between spot market demand and contracted demand. We find that suppliers producing only for the spot market gain from working in industries where contracted demand and spot market demand are positively correlated, whereas suppliers that have forward contracts benefit from working in industries with a negative correlation between demands, since it allows them to better manage risk. In addition, both total industry supply and spot market supply are higher in industries where demands are negatively correlated.
\end{abstract}

Key words: B2B markets; supply chain; spot markets; competition; information

History: Receieved: September 2004; Revised: August 2005, August 2006, and October 2006; Accepted:

November 2006 by Amiya Chakravarty.

\section{Introduction}

Electronic B2B spot markets have captured the attention of many academic researchers and business pundits. Many predicted that eventually B2B spot markets would eliminate forward contracting, at least for the procurement of commodities, because spot markets allow buyers to delay the procurement decision until they have more information about demand and enable them to exploit competition between suppliers to reduce the procurement cost. However, the failure of many B2B spot markets was clear evidence that contracting and long-term relationships with suppliers have merits, which, for many buyers, outweigh the benefits of a potentially lower spot price. Despite high expectations, many spot markets have only a small number of suppliers and limited liquidity. Most companies prefer to build stable longterm relationships with a limited number of suppliers rather than sifting through many offers from suppliers that they have never dealt with before in a B2B market (The Economist 2004).

Researchers argue that buyers optimize procurement over both channels as a risk management technique, because there is a trade-off between contracting earlier, when demand is uncertain, for a known unit price, and waiting to buy on the spot market, after demand is realized, for an uncertain unit price. Consequently, the more buyers contract in advance, the less likely they are to later buy on the spot market, and demand in the two channels (contracts and spot market) is negatively correlated. Nevertheless, even if demand in the two channels originate from two separate groups of buyers, the demand in each channel is not necessarily independent. For example, if the two groups of buyers face the same end-demand stream then we would expect to have a positive correlation between the spot market demand and the contracted demand. In this paper, we model strategic behavior of suppliers in B2B spot markets, allowing for both negative and positive correlation between spot market demand and contracted demand.

There are differences among types of suppliers and how they use spot markets. Many use spot markets for inventory liquidation, offering only the excess inventory that remains after satisfying the contracted demand. However, spot markets are also used by new or small suppliers who do not have loyal customers and forward contracts. Suppliers in this latter group use the spot market as their sole selling channel. In this paper, we model a spot market in a make-to-stock industry with two suppliers, each belonging to one of two types. A Type 1 supplier has loyal customers (forward contracts) and, after observing their demand, 
decides how to split his inventory between these customers and the spot market. A Type 2 supplier does not have loyal customers and produces only for the spot market. The loyal customers' demand, which can take either a high or a low value, and the spot price are unknown at the time of production. The spot market clears with the quantities offered by the suppliers, who compete as a Cournot duopoly.

We examine a market with one supplier of each type and consider both cases in which the Type 2 supplier can and cannot observe the contracted demand. Understandably, this competitive environment can result in many alternative equilibriums. To make the scope of this paper more manageable, we limit most of the analysis to specific classes of equilibriums. One way to classify these equilibriums is in terms of a Type 1 supplier's loyalty to his customers. If a Type 1 supplier only sells on the spot market when he has remaining inventory after satisfying the contracted demand, we call the supplier loyal. Within the set of equilibriums in which the Type 1 supplier is loyal, we focus on those in which he only sells on the spot market when contracted demand is low. We call such equilibriums liquidation equilibriums because the spot market is only used to liquidate excess inventory. Among these equilibriums we devote the most attention to the one in which the Type 1 supplier produces less than the maximum possible contracted demand level. We call this the interactive liquidation equilibrium or ILE because, as our analysis will show, in this equilibrium the actions of the Types 1 and 2 suppliers and the contracted and spot markets are very closely intertwined. For the ILE we address the following research questions: (1) How does the contracted demand of the Type 1 supplier affect the production decision and profit of the supplier who sells only on the spot market? (2) Which supplier type benefits more from the existence of the spot market? (3) Which supplier type benefits more from an increase in spot market demand? (4) Do spot markets have a negative effect on the service provided to contracting customers?

Our results show that in the ILE, when demands on the two channels are independent of each other or positively correlated, the profit and the production quantity of the supplier with no contracts increase as the probability that the Type 1 supplier participates in the spot market increases, and the supplier with no contracts is better off if the Type 1 supplier eliminates contracting altogether. This result does not always hold with negative correlation. We find that when the spot market demand is small, the Type 1 supplier has a higher incentive to invest in expanding the spot market. When the spot market demand exceeds a threshold size, this situation is reversed, and the supplier with no contracts benefits more from making the spot market more prevalent. We show that the supplier with forward contracts benefits from the existence of the spot market more than the supplier with no contracts, and that this result holds with both negative and positive correlation between spot market and contracted demands.

For the ILE, we prove that suppliers producing only for the spot market gain from working in industries where contracted demand and spot market demand are positively correlated, whereas suppliers that have forward contracts benefit from working in industries with a negative correlation between demands, as it allows them to better manage risk. In addition, both total industry supply and spot market supply are higher in industries where demands are negatively correlated. Thus, a positive correlation between demands in the two channels is likely to make buyers worse off, whereas a negative correlation increases industry supply and, generally, improves buyers' welfare. This result agrees with previous research on B2B markets, showing that buyers should use both channels.

This paper is structured as follows. In $\S 2$ we review the relevant literature. In $\S 3$, we construct the model for selling to loyal customers and for spot market clearance. In $\S 4$, we derive production quantity equilibriums, and in $\$ 5$ analyze the ILE and examine which supplier type benefits more from the existence of the spot market, which supplier type is more likely to invest in the spot market in its different stages, and what is the effect of correlation between spot market demand and contracted demand on the production quantities and spot market supply. We briefly discuss other equilibriums in $\S 6$, and the paper concludes in $\S 7$.

\section{Literature Review}

When facing either demand or supply uncertainty it is often valuable to have multiple sources of inputs (Kouvelis et al. 2006). Consequently, questions regarding the optimal number and types of sources are studied in the supply chain literature (e.g., Agrawal and Nahmias 1997, Agrawal et al. 2001, Yan et al. 2003). The emergence and growth of the Internet offers manufacturers and suppliers new avenues to conduct their business (Kouvelis et al. 2006). However, the need to coordinate online and offline activities gives rise to new research questions. Supply chain literature has focused mainly on examining multichannel coordination from the manufacturer's perspective (Peleg et al. 2002, Milner et al. 2006). In this paper we try to fill the gap in the literature and examine multichannel coordination from the suppliers' perspective.

Current research on contracts and spot markets assumes that buyers manage risk by trading off between contracting earlier, when demand is uncertain, for a known unit price, and waiting to buy on the 
spot market, after demand is realized, for an uncertain unit price. For example, Wu et al. (2001, 2002), Araman et al. (2001), Deng and Yano (2002a, b), Seifert et al. (2004), and Sethi et al. (2004) consider situations in which a buyer reserves capacity before demand is known at a per-unit price and after demand is realized can in some way use the spot market as a supplemental supply source. In these models there is a single supplier, and the buyer's strategic behavior is analyzed with spot market prices modeled as exogenous random variables.

Our work differs in that we model strategic behavior of competing suppliers in B2B spot markets with demand correlation between spot market demand and contracted demand, and spot market price is endogenously determined by supply levels. When the number of market participants is limited, as is true in many existing marketplaces, suppliers and buyers may have the power to influence the market. In expectation of this, they may change their decision at the initial contracting stage. Therefore, we model the expected spot market price as a decreasing function of the quantity offered by each supplier.

Tunca (2002) and Lee and Whang (2002) consider spot markets as secondary markets in which parties can readjust (buy and sell) their contracted positions to take advantage of updated information. In these models a monopolistic supplier sells to multiple manufacturers who face uncertain demand. After the manufacturers receive demand signals they can buy and sell to each other on the B2B exchange. These papers do not address the perspective of a seller who is trying to manage multiple sales channels.

Araman and Ozer (2003) and Caldentey and Wein (2006) examine production and allocation decisions for a supplier who sells through two channels, a longterm contract and a spot market, in a single product make-to-stock environment. Caldentey and Wein (2006) assume that buyers split into two groups, based on the contracted price chosen by the seller. Buyers in the first group contract in advance and do not use the spot market, whereas buyers in the second group use only the spot market. Our research differs because we consider a market with two types of suppliers and examine how they affect each other's decisions and profits. The heterogeneity of suppliers is an important distinction between our work and previous work because the success of an online spot market will be affected by the competitive behavior of its participants. An analysis of this behavior must take into account how the value of the spot market differs across suppliers because the market serves different purposes for each supplier type. These differences greatly complicate the analysis and lead to many possible equilibriums.

\section{Model Formulation}

We examine a make-to-stock industry with two types of suppliers. A Type 1 supplier has loyal customers (contracts) to whom he sells at a fixed unit price. The demand from these customers is unknown at the time he makes his production decision. After observing the contracted demand, this supplier decides how to split his inventory between his loyal customers and a spot market, where he competes with other suppliers. A Type 2 supplier does not have loyal customers (contracts) and thus produces only for the spot market. The spot market price is determined by the total quantity offered by all suppliers. Here, we assume that only two suppliers use the spot market and that, unless otherwise specified, Supplier $i$ is of Type $i(i=1,2)$. The timing of the game is depicted in Figure 1.

In the environment we model, production takes place before demand from forward contracts is realized. At the time Supplier 1 makes the production decision, the demand from his loyal customers, $D$, is believed to be high with probability $\alpha$ and low with probability $(1-\alpha)$. We assume that the contracted unit price, $w$, is exogenously given and that there is a penalty cost, $k$, for each unit of unsatisfied demand. Both suppliers incur the same per unit production cost, $c$, and can also sell excess inventory for a salvage value of $s$ per unit, where $s<c<w$. Table 1 summarizes the model notation.

The spot market clears with the quantities offered by the suppliers, who compete as a Cournot duopoly. The demand curve (spot price as a function of quantity demanded) is assumed to be linear with slope normalized to 1 . The spot market price given by

$$
p_{M}=B+d-\sum_{i=1}^{2} q_{i},
$$

where $p_{M}$ is the clearing price and $q_{i}$ is the quantity offered on the spot market by Supplier $i . B$ and $d$ are in price units, and the coefficient of $q_{i}$ is 1 [price/quantity]. $B$ and $d$, respectively, represent the known and unknown components of the demand intercept (see Tunca 2002).

The contracted demand can serve as a signal regarding the spot market price: High contracted demand can increase (decrease) expectations regarding the spot market price when demands on the two channels are positively (negatively) correlated. Hence, after observing the contracted demand, Supplier 1

Figure 1 Timing of the Decisions and the Information Available

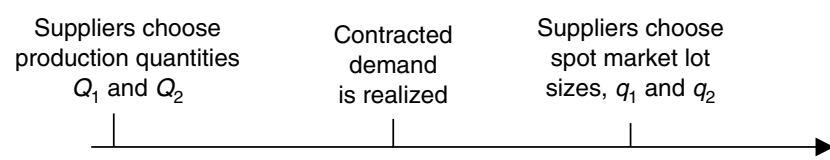




\begin{tabular}{|c|c|}
\hline ble 1 & Notation \\
\hline$D$ & $\begin{array}{l}\text { Demand from loyal customers, a discrete random variable with } \\
\text { support set }\{L, H\} \text {. }\end{array}$ \\
\hline$\alpha$ & Probability of high contracted demand. \\
\hline$w$ & Unit price for loyal customers. \\
\hline$k$ & Penalty cost for each unit not delivered to loyal customers. \\
\hline$c$ & Unit production cost. \\
\hline$Q_{i}$ & Quantity produced by supplier $i, i \in\{1,2\}$. \\
\hline$q_{i}$ & Quantity offered on the spot market by supplier $i, i \in\{1,2\}$. \\
\hline & Unit price on the spot market. \\
\hline$\pi_{i}\left(Q_{i}\right)$ & Profit of supplier $i$ as function of his production lot. \\
\hline$s$ & Salvage value for unsold units. \\
\hline$\beta$ & $\begin{array}{l}\text { Parameter reflecting correlation between spot and } \\
\text { contracted demand. }\end{array}$ \\
\hline
\end{tabular}

updates his belief regarding the distribution of the spot market price. In some markets, Supplier 2 can also observe Supplier 1's contracted demand (whether it is high or low) before offering a quantity on the spot market. We refer to such markets as transparent. In nontransparent markets, where Supplier 2 does not observe Supplier 1's contracted demand, he offers his entire inventory on the spot market. In transparent markets, Supplier 2 might choose, under some conditions, to offer only part of his inventory on the spot market. Therefore, the set of feasible production quantity equilibriums depends on the assumption we make regarding market transparency.

To model dependency between the demands, we first define the distribution of $d$ conditional on the value of the contracted demand, $D$. We model $d \mid D$ as a random variable from the normal distribution with mean $\beta(D-E[D])$ and standard deviation $\sigma$. Given the above distribution of $d \mid D$, the random variable $d$ is a mixture of normal distributions (see Greene 2008, p. 432), with mean $\alpha \beta(H-E[D])+$ $(1-\alpha) \beta(L-E[D])=0$ and variance $\sigma^{2}+\beta^{2} \operatorname{VAR}[D]$. When $\beta$ is zero, the spot market demand and the contracted demand are independent of each other, and $d$ is drawn from the standard normal distribution, $N\left(0, \sigma^{2}\right)$. When $\beta>0(\beta<0)$, the demands on the two channels are positively (negatively) correlated. That is, when $\beta>0$ we expect the deviation of the contracted demand from its expected value, and the deviation of the spot market demand from its expected value, to be in the same direction. For example, if end-user demand for gasoline is rising, firms in the gasoline industry will purchase larger quantities than expected, via both contracts and spot markets. Hence, the demand for gasoline in the two channels is positively correlated. When $\beta<0$, we expect the deviations from the expected values to be in opposite directions. For example, in an industry with a limited number of buyers, a large buyer might split his demand between the two channels as a risk management technique. In this case, observing low contracted demand increases the probability of high spot market demand, and the demands on the two channels are negatively correlated. Examining the inverse demand curve, $\sum_{i=1}^{2} q_{i}=1[$ quantity $/$ price $] \times B+$ 1 [quantity/price] $\times d-1$ [quantity/price $] \times p_{M}$, it is clear that $B$ is an indicator for the size of the spot market demand. We denote $B+\beta(H-E[D])$ by $B_{H}$ and $B+\beta(L-E[D])$ by $B_{L}$, and assume that the unit production cost, $c$, is such that $B>c$. Otherwise, a supplier with no contracts does not participate in the spot market when the market is nontransparent. We expect that negative demand correlation is caused by buyers optimizing procurement across both channels. Hence, we assume that $\beta \geq-2$, so that the adjustment to the expected spot market demand is not larger than twice the realized contracted demand deviation from its expected value.

\subsection{Supplier 1's Problem}

Supplier 1 faces a two-stage optimization problem. In the first stage he needs to make the production decision, $Q_{1}$, knowing only the distributions of the contracted demand and spot market price. In the second stage, after observing contracted demand, he updates his belief regarding the spot market price and makes the inventory allocation decision.

When contracted demand is high, Supplier 1 chooses $q_{1}$ that maximizes his expected revenue from both channels, given by

$$
\begin{aligned}
& R_{1}\left(q_{1} \mid H\right)=w \operatorname{Min}\left.H, Q_{1}-q_{1}\right)-k\left(H-\left(Q_{1}-q_{1}\right)\right)^{+} \\
&+q_{1}\left(B_{H}-q_{2}(H)-q_{1}\right)^{+} \\
&+s\left(Q_{1}-q_{1}-H\right)^{+} \\
& \text {subject to } 0 \leq q_{1} \leq Q_{1} .
\end{aligned}
$$

Similarly, when contracted demand is low, Supplier 1 chooses $q_{1}$ that maximizes his expected revenue as given by

$$
\begin{aligned}
& R_{1}\left(q_{1} \mid L\right)=w \operatorname{Min}\left(L, Q_{1}-q_{1}\right)-k\left(L-\left(Q_{1}-q_{1}\right)\right)^{+} \\
&+q_{1}\left(B_{L}-q_{2}(L)-q_{1}\right)^{+} \\
&+s\left(Q_{1}-q_{1}-L\right)^{+} \\
& \text {subject to } 0 \leq q_{1} \leq Q_{1} .
\end{aligned}
$$

The derivative of Supplier 1's revenue with respect to $q_{1}$ is given by

$$
\begin{aligned}
& \frac{\partial R\left(q_{1} \mid D\right)}{\partial q_{1}} \\
& =\left\{\begin{array}{l}
\left(B_{D}-q_{2}(D)-2 q_{1}\right)^{+}-s \quad \text { if } 0 \leq q_{1}<\left(Q_{1}-D\right)^{+} \\
\left(B_{D}-q_{2}(D)-2 q_{1}\right)^{+}-(w+k) \text { if } q_{1} \geq\left(Q_{1}-D\right)^{+} .
\end{array}\right.
\end{aligned}
$$

In this paper, we limit our attention to equilibriums in which the forward contract, specified by $w$ and $k$, 
is such that Supplier 1 uses his inventory to satisfy demand from loyal customers (contracts) before offering units on the spot market. That is, we are interested in equilibriums in which the optimal amount allocated to the spot market satisfies $q_{1} \leq\left(Q_{1}-D\right)^{+}$, for both $D=H$ and $D=L$. Notice that there cannot be an equilibrium in which Supplier 1 always undersatisfies contracted demand by selling more than $\left(Q_{1}-D\right)^{+}$units on the spot market for any realization of $D$, because then his profit would be strictly increasing in $Q_{1}$, and he would deviate and produce more. However, there can be equilibriums in which $q_{1}>\left(Q_{1}-H\right)^{+}$or $q_{1}>$ $\left(Q_{1}-L\right)^{+}$.

We are assuming that customers who contract in advance can negotiate values of $w$ and $k$ such that Supplier 1 gives them priority over the spot market for any realization of the contracted demand. Modeling such a negotiation process is beyond the scope of this paper, and thus we treat $w$ and $k$ as exogenously given and assume that their sum is high enough to ensure Supplier 1 stays "loyal" to his customers. That is, we assume $\partial R\left(q_{1} \mid D\right) /\left.\partial q_{1}\right|_{q_{1}=\left(Q_{1}-D\right)^{+}} \leq 0$ for both $D=H$ and $D=L$, which holds if and only if

$$
\begin{array}{r}
w+k \geq \operatorname{Max}\left\{B_{H}-q_{2}(H)-2\left(Q_{1}-H\right)^{+},\right. \\
\left.B_{L}-q_{2}(L)-2\left(Q_{1}-L\right)\right\} .
\end{array}
$$

Supplier 1's expected spot market revenue is given by

$$
\begin{aligned}
R_{S M}\left(Q_{1}\right)= & \alpha q_{1}(H)\left[B_{H}-q_{2}(H)-q_{1}(H)\right]^{+} \\
& +(1-\alpha) q_{1}(L)\left[B_{L}-q_{2}(L)-q_{1}(L)\right]^{+} .
\end{aligned}
$$

Given that we are interested in equilibriums in which Supplier 1 finds it optimal to be loyal, before observing the contracted demand Supplier 1 solves for the optimal production quantity, maximizing his expected profit as given in (6).

$$
\begin{aligned}
\pi_{1}\left(Q_{1}\right)=\alpha w \text { Min } & \left(Q_{1}, H\right)+(1-\alpha) w L \\
& -\alpha k\left(H-Q_{1}\right)^{+}+R_{S M}\left(Q_{1}\right)-c Q_{1} \\
& +(1-\alpha) s\left(Q_{1}-L-q_{1}(L)\right)^{+} .
\end{aligned}
$$

Notice, that for $\beta>-2$, Supplier 1 would never find it optimal to sell units for the salvage value $s$ when contracted demand is high.

\subsection{Supplier 2's Problem in Transparent Markets}

In markets where Supplier 2 observes the contracted demand, Supplier 2 faces a two-stage optimization problem. In the second stage, after observing the contracted demand, the supplier maximizes his revenue as given by $R_{2}\left(q_{2} \mid D\right)=q_{2}\left(B_{D}-q_{2}-q_{1}(D)\right)^{+}+$ $s\left(Q_{2}-q_{2}\right)$, subject to $0 \leq q_{2} \leq Q_{2}$. The revenue function is strictly concave for $q_{2}<B_{D}-q_{1}(D)$, and taking the first-order condition we find Supplier 2's best response to be

$$
q_{2}(D)=\operatorname{Min}\left[Q_{2}, 0.5\left(B_{D}-q_{1}(D)-s\right)^{+}\right] .
$$

In the first stage of the game, before observing the contracted demand, Supplier 2 chooses the production quantity $Q_{2}$ that maximizes his profit given by

$$
\begin{aligned}
\pi_{2}\left(Q_{2}\right)= & \alpha\left(q_{2}(H)\left(B_{H}-q_{2}(H)-q_{1}(H)\right)^{+}+s\left(Q_{2}-q_{2}(H)\right)\right) \\
& +(1-\alpha)\left(q_{2}(L)\left(B_{L}-q_{2}(L)-q_{1}(L)\right)^{+}\right. \\
& \left.+s\left(Q_{2}-q_{2}(L)\right)\right)-c Q_{2} . \quad(8)
\end{aligned}
$$

It is easy to show that there cannot be equilibrium in which Supplier 2 offers less than $Q_{2}$ units on the spot market for each realization of the contracted demand because in such a case Supplier 2 would deviate and produce less. Hence, there are only three possible scenarios: either

$$
q_{2}(H)=Q_{2}, \quad q_{2}(L)=0.5\left(B_{L}-q_{1}(L)-S\right)^{+}<Q_{2},
$$

and

$$
Q_{2}\left(q_{1}(H)\right)=0.5\left(B_{H}-q_{1}(H)-s\right)-(c-s) /(2 \alpha) ;
$$

or,

$$
q_{2}(L)=Q_{2}, \quad q_{2}(H)=0.5\left(B_{H}-q_{1}(H)-S\right)^{+}<Q_{2},
$$

and

$$
Q_{2}\left(q_{1}(L)\right)=\left(B_{L}-q_{1}(L)-s\right) / 2-(c-s) / 2(1-\alpha) ;
$$

or it is optimal for Supplier 2 to offer $Q_{2}$ units on the spot market regardless of the observed value of the contracted demand and thus $Q_{2}\left(E\left[q_{1}\right]\right)=0.5\left(B-E\left[q_{1}\right]-c\right)^{+}$.

\subsection{Supplier 2's Problem in Nontransparent Markets}

In markets where Supplier 2 cannot observe the contracted demand, he faces a one-stage game in which $q_{2}(H)=q_{2}(L)=Q_{2}$, and his expected profit is given by

$$
\pi_{2}\left(Q_{2}\right)=Q_{2}\left(B-Q_{2}-E\left[q_{1}\right]\right)^{+}-c Q_{2} .
$$

Because $\pi_{2}$ is concave in $Q_{2}$ we can use the firstorder condition to write Supplier 2's best response as a function of Supplier 1's expected spot market lot size:

$$
Q_{2}\left(E\left[q_{1}\right]\right)=0.5\left(B-E\left[q_{1}\right]-c\right)^{+} .
$$

\section{Analysis}

In what follows, we first derive production quantities equilibriums for nontransparent markets, in which a Type 2 supplier cannot observe the realization of the contracted demand of a Type 1 supplier. Then, for the case of transparent markets, we derive equilibriums in which $Q_{1}<H$. In this section we only present equilibriums in which Supplier 1 is loyal. In addition, to reduce the number of equilibriums that must be considered and to simplify exposition, we limit the parameter values to those for which both suppliers have positive production quantities and the expected spot price is positive for every realization of the contracted demand. 


\subsection{Nontransparent Markets}

When Supplier 2 cannot observe the realization of the contracted demand he faces a one stage game and thus $q_{2}(H)=q_{2}(L)=Q_{2}$. Supplier 1 observes the contracted demand and, given the loyalty assumption, allocates inventory to the spot market according to Lemma 1.

LEMMA 1. If the production quantities $\left(Q_{1}, Q_{2}\right)$ satisfy inequality (5), then Supplier 1's optimal spot market lot size when $\beta>-2$ is given by

$$
q_{1}(D)=\left\{\begin{array}{c}
\operatorname{Min}\left(Q_{1}-L, \frac{\left(B_{L}-Q_{2}-s\right)^{+}}{2}\right) \\
\text { if } D=L \\
\operatorname{Max}\left(0, Q_{1}-H\right) \quad \text { if } D=H,
\end{array}\right.
$$

with expected spot market revenue given by

$$
\begin{aligned}
R_{S M}\left(Q_{1}\right)= & \alpha q_{1}(H)\left[B_{H}-Q_{2}-q_{1}(H)\right] \\
& +(1-\alpha) q_{1}(L)\left[B_{L}-Q_{2}-q_{1}(L)\right] .
\end{aligned}
$$

Table 2 presents feasible equilibriums when there is one supplier of each type. To simplify notation we introduce $W=w+k$. The derivations appear in the Online Supplement (available at http://www.poms. org/journal/supplements/), and existence conditions for equilibriums T1-T4 can be obtained from the authors by request.
Given the complexity of the equilibrium existence conditions, it is not possible to comprehensively verify analytically if these equilibriums can coexist. It can be shown that $\mathrm{T} 1$ cannot coexist with $\mathrm{T} 2$ or $\mathrm{T} 3$, that $\mathrm{T} 4$ cannot coexist with the ILE or T2, and that T2 cannot coexist with the ILE. Numerically checking millions of parameter combinations, we have found examples of equilibriums T1 and T3 coexisting with T4. We have not found any examples of these equilibriums coexisting with the ILE. Examining Table 2, we learn that in equilibriums in which $Q_{1}>H$, the expected spot market supply is the same as when we have two Type 2 suppliers in the market, and Supplier 1's contracts do not affect Supplier 2's behavior. In this paper, we focus on the single equilibrium in which $L<Q_{1}<H$ (the ILE) and give a brief discussion of the intuition for the other four equilibriums in §6. In the ILE, when contracted demand is low, Supplier 1 sells $\left(Q_{1}-L\right)$ units on the spot market. When contracted demand is high, he sells his entire inventory to his loyal customers. The ILE is the only equilibrium in which Supplier 1 incurs a penalty cost when contracted demand is high, because his inventory is not sufficient to satisfy a high level of contracted demand. It is also the only equilibrium in which the contracted unit price, $w$, affects the production quantities. The ILE prevails when the value of $W$ is high enough to make Supplier

\begin{tabular}{|c|c|}
\hline Equilibrium & The equilibrium values of $Q_{1}, Q_{2}$ \\
\hline $\begin{aligned} \mathrm{T} 1: & Q_{1}>H \\
& Q_{1}-L<\frac{B_{L}-Q_{2}-s}{2}\end{aligned}$ & $Q_{1}=E[D]+(B-C) / 3 \quad Q_{2}=(B-C) / 3$ \\
\hline T2: $\begin{aligned} Q_{1} & >H \\
& Q_{1}-L \geq \frac{B_{L}-Q_{2}-s}{2}\end{aligned}$ & $\begin{array}{l}Q_{1}=H+0.5\left(B_{H}-(B-C) / 3-c / \alpha\right)+0.5(1-\alpha) s / \alpha \\
Q_{2}=(B-C) / 3\end{array}$ \\
\hline T3: $\begin{array}{ll}Q_{1}=H \\
& Q_{1}-L<0.5\left(B_{L}-Q_{2}-s\right)\end{array}$ & $Q_{1}=H \quad Q_{2}=0.5(B-c-(1-\alpha)(H-L))$ \\
\hline T4: $\begin{aligned} Q_{1}=H \\
\\
Q_{1}-L \geq 0.5\left(B_{L}-Q_{2}-S\right)\end{aligned}$ & $Q_{1}=H \quad Q_{2}=\frac{B+\alpha B_{H}-2 c+(1-\alpha) s}{3+\alpha}$ \\
\hline ILE: $L<Q_{1}<H$ & $Q_{1}=Q_{1}^{0}-\beta \frac{2 \alpha(H-L)}{3+\alpha} \quad Q_{2}=Q_{2}^{0}+\beta \frac{(1-\alpha) \alpha(H-L)}{3+\alpha}$ \\
\hline$Q_{1}-L<\frac{B_{L}-Q_{2}-s}{2}$ & $Q_{1}^{0}=L+\frac{2 \alpha W-2 c+(1-\alpha)(B+c)}{(1-\alpha)(3+\alpha)} \quad Q_{2}^{0}=\frac{(1+\alpha) B-c-\alpha W}{3+\alpha}$ \\
\hline & $\begin{array}{l}\text { Existence condition for the ILE: } \\
\text { - } 2 \alpha W-2 c+(1-\alpha)(B+C)>2(1-\alpha) \alpha \beta(H-L) \\
\text { - } 2 \alpha W-2 c+(1-\alpha)(B+C)<(1-\alpha)(3+\alpha+2 \beta \alpha)(H-L) \\
\text { - } C>\alpha W+(1-\alpha) S \\
\text { - } 3 W \geq 2 B+C+3 \beta(1-\alpha)(H-L) \\
\text { - } B+\alpha B_{H}-c>\alpha W \\
\text { - } 3 B_{H}-B+C+\alpha W \geq 0\end{array}$ \\
\hline
\end{tabular}
1 give priority to demand originating from his loyal

Table 2 Equilibriums in Which Supplier 1 Is Loyal in Nontransparent Markets 
customers, but is not high enough to make him produce $H$ units, and, in addition, the expected spot market demand is such that Supplier 1 does not use the spot market as an additional channel. He only uses it when contracted demand is low. We find this equilibrium to be of most interest, and we believe it captures the current situation of the majority of online marketplaces that position themselves as liquidation venues for overstocks. Notice that this is also the only equilibrium in which both production quantities are functions of $\beta$, the correlation parameter. Next we search for production quantities equilibriums in which $L<$ $Q_{1}<H$ under the market transparency assumption.

\subsection{Market Transparency}

In markets where Supplier 2 observes the status of the contracted demand he uses it as a signal for the spot market price and might choose, under some conditions, to offer only part of his inventory on the spot market. Hence, assuming market transparency we expect to find a different set of production quantity equilibriums than those listed in Table 2. Given our interest in the ILE in nontransparent markets, we identify equilibriums in which Supplier 1 is loyal and $Q_{1}<H$ for transparent markets. We acknowledge that equilibriums with $Q_{1}=H$ or $Q_{1}>H$ can also exist under market transparency.

As derived in \$3, Supplier 2's best response after observing the contracted demand is given by $q_{2}(D)=$ $\operatorname{Min}\left[Q_{2}, 0.5\left(B_{D}-q_{1}(D)-s\right)^{+}\right]$, and Supplier 1 stays loyal to his loyal customers if and only if $W \geq$ $\operatorname{Max}\left(B_{H}-q_{2}(H)-2\left(Q_{1}-H\right)^{+}, B_{L}-q_{2}(L)-2\left(Q_{1}-L\right)\right)$. We find that when contracted demand and spot market demand are independent or positively correlated, the ILE is the only feasible equilibrium with $Q_{1}<H$. This is true with or without market transparency. When demands are negatively correlated, market transparency can lead to one other alternative equilibrium in which $Q_{1}<H$ and Supplier 2 does not sell on the spot market everything he produces if he knows contracted demand was high. We call this the alternative interactive equilibrium (AIE). Table 3 lists the two possible liquidation equilibriums with $Q_{1}<H$ under market transparency. The derivation of the equilibriums is similar to the one described in the Online Supplement for Table 2. The results are summarized in Propositions 1 and 2, and the proofs are in the Online Supplement.

Proposition 1. When demand is positively correlated, the ILE is the only equilibrium with $L<Q_{1}<H$, loyal Supplier $1, Q_{2}>0$, and a positive expected spot price for every realization of $D$, whether Supplier 2 observes the contracted demand or not. Production quantities are given by

$$
\begin{gathered}
Q_{1}^{\mathrm{ILE}}=L+\frac{(1-\alpha)(B+c)-2 c+2 \alpha W}{(3+\alpha)(1-\alpha)}-\beta \frac{2 \alpha(H-L)}{3+\alpha} \\
Q_{2}^{\mathrm{ILE}}=\frac{B(1+\alpha)-c-\alpha W}{(3+\alpha)}+\beta \frac{(1-\alpha) \alpha(H-L)}{3+\alpha},
\end{gathered}
$$

and $q_{2}(H)=q_{2}(L)=Q_{2}^{\mathrm{ILE}}$.

Proposition 2. When demand is negatively correlated and Supplier 2 does not observe D, the ILE, given in Equations (12) and (13), is the only equilibrium with $L<Q_{1}<H$, loyal Supplier $1, Q_{2}>0$, and a positive expected spot price for every realization of D. If Supplier 2

Table 3 Possible Equilibriums with $L<Q_{1}<H$ Under Market Transparency

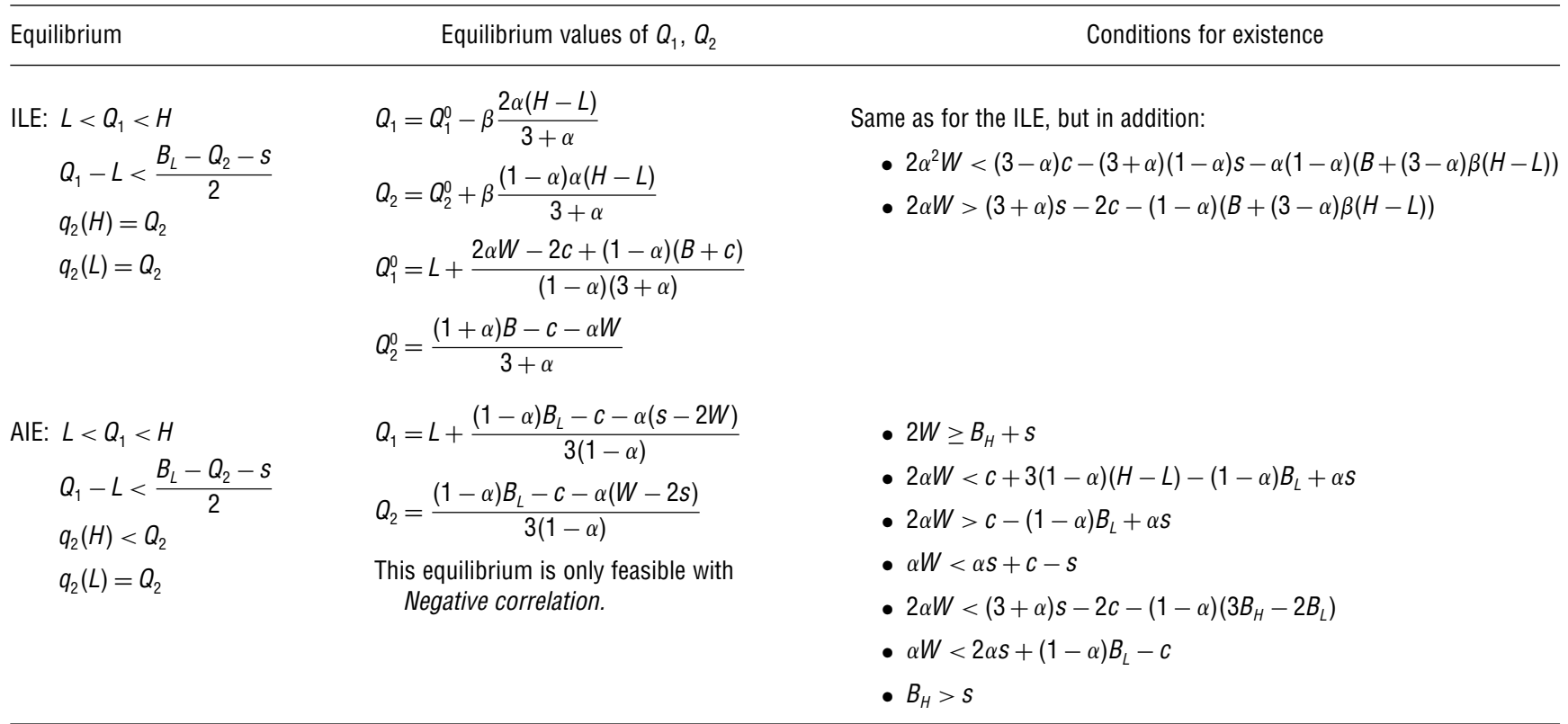


observes $D$, then there can also be an equilibrium (AIE) in which: $L<Q_{1}<H, q_{2}(H)<Q_{2}$, and $q_{2}(L)=Q_{2}$, given by

$$
\begin{gathered}
Q_{1}^{\mathrm{AIE}}=L+\frac{B_{L}}{3}-\frac{c+\alpha(s-2 W)}{3(1-\alpha)} \\
Q_{2}^{\mathrm{AIE}}=\frac{B_{L}}{3}-\frac{c+\alpha(W-2 s)}{3(1-\alpha)}
\end{gathered}
$$

\section{Interactive Liquidation Equilibrium}

Here, we analyze the ILE to see how the activities in the contract market and spot market interact and the effect of demand correlation. Based on Table 2, with one Type 1 and one Type 2 supplier, under the ILE, suppliers' expected profits are given by

$$
\begin{gathered}
\pi_{1}^{\mathrm{ILE}}=L(w-c)-\alpha k(H-L)+(1-\alpha)\left(Q_{1}^{\mathrm{ILE}}-L\right)^{2} \\
\pi_{2}^{\mathrm{ILE}}=\frac{((1+\alpha) B-\alpha W-c)^{2}}{(3+\alpha)^{2}}=\left(Q_{2}^{\mathrm{ILE}}\right)^{2},
\end{gathered}
$$

and the expected spot market price is

$$
\begin{aligned}
E\left[p_{M}\right]^{\mathrm{ILE}}= & \frac{(1+\alpha)(B+c)+c-\alpha W}{3+\alpha} \\
& +\beta \frac{\alpha(1-\alpha)(H-L)}{3+\alpha} .
\end{aligned}
$$

Notice, that although the ILE production quantities depend only on the sum of $w$ and $k$, denoted by $W$, Supplier 1's profit depends on the relative values of $w$ and $k$. For the rest of this section we assume that the conditions for the existence of the ILE hold. It is understood that these conditions are somewhat different depending upon whether or not there is market transparency.

\subsection{Effect of Contracted Demand on the Spot Market}

We now consider how the behavior of Supplier 1 affects the production quantity and profit of Supplier 2. A naïve observer might expect that in spot markets Supplier 2 would be worse off if Supplier 1 participated more often because it would create more competition. One might also expect that a supplier dedicated to only the spot market would profit more from the spot market than a firm that only used the spot market for liquidation of excess inventory. In fact, we find that just the opposite is true for both these expectations.

In the ILE, the probability that Supplier 1 participates in the spot market is $(1-\alpha)$. As this probability increases ( $\alpha$ decreases), there are several effects. With positive demand correlation $(\beta>0)$, an increase in $(1-\alpha)$ means higher upward adjustment to the expected spot price when contracted demand is high and smaller downward adjustment when contracted demand is low. Because Supplier 1 participates in the spot market only when expected spot market demand is low, and because as $(1-\alpha)$ increases, there is higher probability that demand indeed will be low, he produces less, mitigating the competition. When demands are high, Supplier 2 reaps all the benefits from the higher expected spot price (he faces no competition), which increases in $(1-\alpha)$. When $\beta<0$, an increase in $(1-\alpha)$ means higher downward adjustment to the expected spot price when contracted demand is high and smaller upward adjustment when contracted demand is low. Here, Supplier 1 participates in the spot market when the expected spot market demand is high and so has higher incentive to produce more. When Supplier 2 has no competition, the spot market demand tends to be low.

In the ILE the net result of the above effects is that when contract demand and spot market demand are independent or positively correlated, Supplier 2 benefits when Supplier 1's participation in the spot market is more frequent because of a decrease in $\alpha$. This is not always the case when demand in the two markets is negatively correlated. These results are summarized in Proposition 3.

Proposition 3. In the ILE, if $\beta \geq 0$ the production lot and profit of Supplier 2 increase as the probability that Supplier 1 participates in the spot market increases.

Proposition 4 shows that in the ILE, a supplier with contracts actually profits from the existence of the spot market more than a supplier who produces only for the spot market. The increase in Supplier 1's profit from access to a spot market is greater than the entire profit of Supplier 2. The intuition for this is that the spot market serves two roles for a Type 1 supplier. First, it is a selling channel like it is for a Type 2 supplier. Second, it increases the salvage value of excess inventory making it economical to satisfy more of the contracted demand.

Proposition 4. In the ILE, Supplier 1 benefits from the existence of the spot market more than Supplier 2, whether spot market demand and contracted demand are independent, positively correlated, or negatively correlated.

In our model an increase in the size of the spot market is reflected in an increase in the parameter $B$. In Proposition 5, we show that when $B$ is small, the Type 1 supplier has a greater incentive to increase the size of the spot market. When the market size exceeds a certain level, i.e., $B$ is large enough, the incentive to invest in expanding the market is greater for the Type 2 supplier. When demands on the two markets are positively correlated, the critical mass is smaller than when demands are negatively correlated. That is, in industries where demands on the two channels are positively correlated, we expect suppliers who do not 
have forward contracts to start investing in spot markets earlier.

Proposition 5. In the ILE, a marginal increase in B increases both suppliers profits, and the increase in Supplier 2 's profit is larger if and only if $B>W-\beta(1-\alpha)(H-L)$.

\subsection{Effect of the Spot Market on Contracting and Prevalence of Contracting}

We now consider how the spot market might affect long-term relationships (contracts) between suppliers and their customers. Other papers have pointed out that as spot markets or secondary markets become more prevalent, forward contracting will become obsolete. Wu and Kleindorfer (2003) show that a seller, with perfect market access, has no reason to contract. Tunca (2002) shows that if the exchange is sufficiently liquid, parties choose not to engage in contracting at all. However, these papers assume that spot market demand and contracted demand originate from the same buyer(s), and so, an increase in the spot market demand comes at the expense of contracted demand (demands are negatively correlated).

In the ILE, we consider cases in which $c>\alpha(k+w)$ $+(1-\alpha) s$ (see Table 2). Hence, without a spot market, Supplier 1 engages in contracts and produces $L$ units when his expected profit from doing so is nonnegative. With access to the spot market, his profit is $\pi_{1}^{E 2}=(B-c)^{2} / 9$ if he does not contract, and is given by Equation (15) if he does. In this section, $\pi_{i}^{\mathrm{ILE}}$ denotes the profit of supplier $i$ in the ILE with one supplier of each type, $\pi_{i}^{E 2}$ denotes the profit of supplier $i$ when both suppliers are Type 2, and $\pi_{1}^{L}$ denotes Supplier 1's profit without a spot market.

If $\pi_{1}^{\mathrm{ILE}}-\pi_{1}^{E 2}>0$ and Supplier 1's expected profit from contracts with no spot market, $\pi_{1}^{L}=$ $\operatorname{Max}(0, L(w-c)-\alpha k(H-L))$, is zero, then it is not profitable for him to engage in forward contracts with fixed unit price $w$. However, with access to the spot market, he finds it optimal to contract. The intuition behind this result is clear: with no spot market the salvage value for unsold units is $\$ s$. But, with access to the spot market, the larger (though decreasing in quantity) expected spot price reduces the risk of overestimating contracted demand, hence making contracting more appealing. In Figure 2 we see that for some situations $\pi_{1}^{L}=0$ and $\pi_{1}^{\mathrm{IEE}}-\pi_{1}^{E 2}>0$. Clearly, this is not always the case. In Figure 3, Supplier 1 prefers to use the spot market and not engage in contracts. That is, $\pi_{1}^{E 2}-\pi_{1}^{\mathrm{ILE}}>0$, for a wide range of $\alpha$ values for which $\pi_{1}^{L}=0$. Hence, as much as buyers would like to set lower values of $w$ and higher values of $k$ to reduce procurement cost and ensure supply, they must be careful, since if $w$ decreases and $k$ increases, Supplier 1 might choose not to contract, even when he can liquidate inventory on the spot market.
Figure 2 Supplier Profit as a Function of $\alpha$, When $w=\$ 60, k=\$ 5$, $c=\$ 50, \beta=0$, and $s=\$ 0$

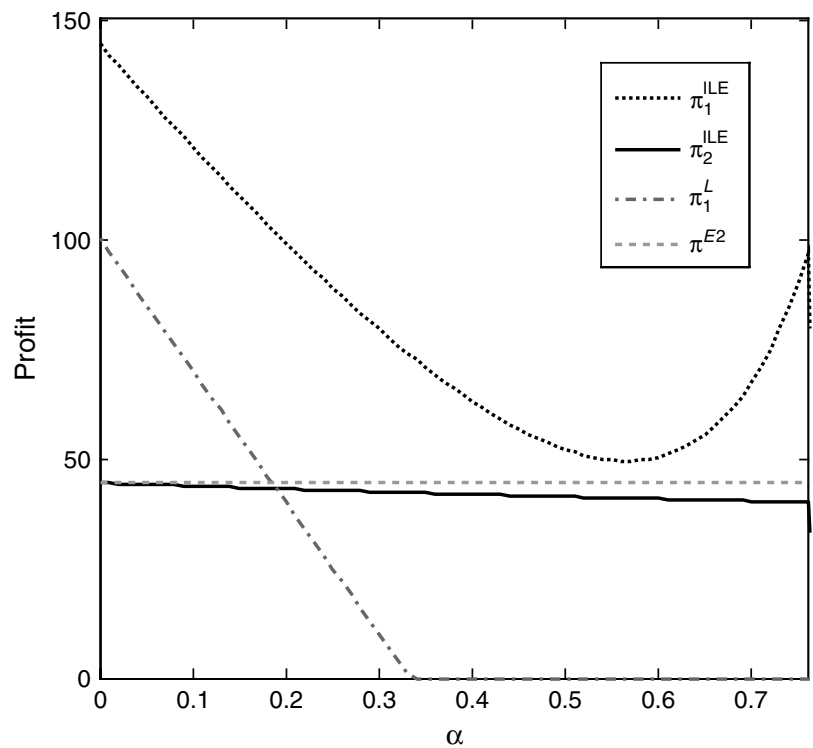

Note. $C=50, w=60, k=5, L=10, H=70, B=70, \beta=0, s=0$.

Notice that based on Proposition $4, \pi_{1}^{L}>0$ is sufficient for $\pi_{1}^{\mathrm{ILE}}>\pi_{2}^{\mathrm{ILE}}$. Hence, if contracting takes place when there is no spot market, Supplier 1's profit from contracts and spot market is higher than Supplier 2's profit. However, if in addition $\pi_{1}^{E 2}>\pi_{1}^{\mathrm{ILE}}$, Supplier 1 eliminates contracting when using the spot market. It is also interesting to note that in both Figures 2 and $3 \pi_{2}^{E 2}>\pi_{2}^{\mathrm{ILE}}$, meaning that Supplier 2 does better when competing against another Type 2 supplier than when competing against a Type 1 supplier. The

Figure 3 Supplier Profit as a Function of $\alpha$, When $w=\$ 60, k=\$ 10$, $c=\$ 50, \beta=0$, and $s=\$ 0$

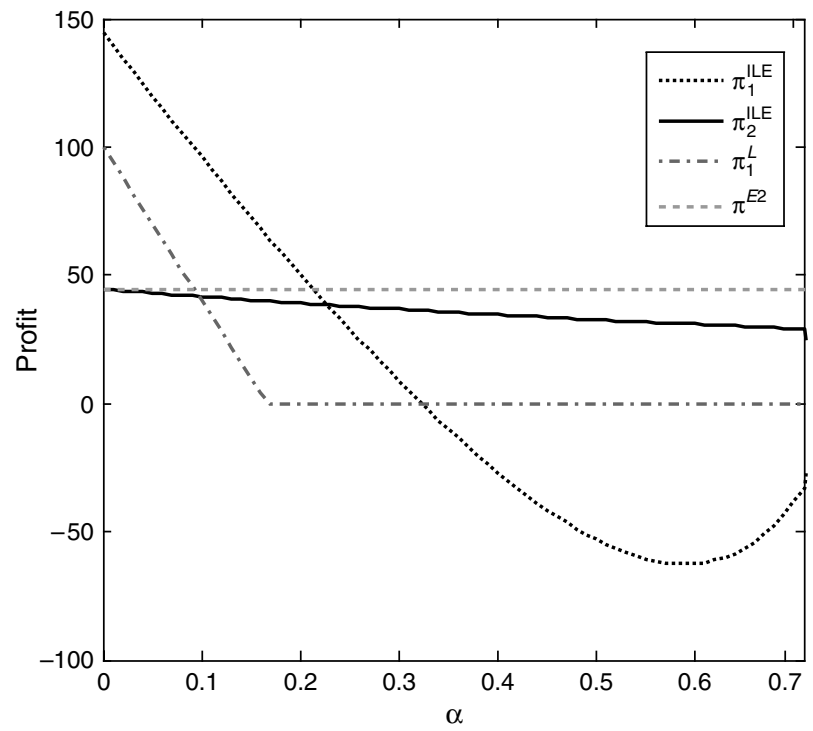

Note. $C=50, w=60, k=10, L=10, H=70, B=70, \beta=0, s=0$. 
reason for this somewhat surprising result is similar to the reasoning behind Proposition 3. A competing Type 2 supplier will, on average, sell smaller quantities on the spot market than a Type 1 supplier in the ILE.

\subsection{Correlation Between Demands}

In industries where contracted demand and spot market demand originate from two independent groups of buyers, but all buyers face the same endcustomers demand, a high (low) level of contracted demand increases (decreases) the expected spot market demand. On the other hand, in industries where contracted demand increases at the expense of spot market demand, for example, because buyers optimize procurement using both channels, a high (low) level of contracted demand decreases (increases) the expected spot market demand. Both arguments are compelling, depending on the circumstances and the industry examined.

In the ILE, the production quantities change linearly with the correlation parameter $\beta$ (see Table 2). As $\beta$ increases, Supplier 1 produces less because he expects a lower spot price (smaller $B_{L}$ ) when he needs to use the spot market. Supplier 2, on the other hand, produces more because he expects a higher spot price when $D=H$ and less competition when $D=L$. Because Supplier 1 uses the spot market only when contracted demand is low, he does not benefit from the increase in the expected spot price when contracted demand is high. Hence, as $\beta$ increases, the spot market becomes less attractive for Supplier 1 but more attractive for Supplier 2.

When demands are negatively correlated, low contracted demand increases the expected spot market demand, and hence, the spot market channel complements the contracts channel, and Supplier 1 can use it to manage risk. On the other hand, Supplier 2 is worse off (with negative correlation) and he produces less. We conclude that positive correlation between the demands favors suppliers that work solely on the spot market, whereas negative correlation favors suppliers that have contracts (they can better manage risk).

Defining $Q_{i}(\beta)$ as the quantity produced by Supplier $i$ in the ILE as a function of $\beta$, we can write the change in total industry and spot market supply when $\beta$ increases by $\Delta$ as:

$$
\begin{aligned}
\text { Industry supply change } & =\sum_{i}\left(Q_{i}(\beta+\Delta)-Q_{i}(\beta)\right) \\
& =-\Delta(1+\alpha)(E[D]-L) /(3+\alpha)
\end{aligned}
$$

Spot market supply change

$$
\begin{aligned}
& =E\left[q_{1}(\beta+\Delta)-q_{1}(\beta)\right]+Q_{2}(\beta+\Delta)-Q_{2}(\beta) \\
& =-\Delta(1-\alpha)(E[D]-L) /(3+\alpha) .
\end{aligned}
$$

We can observe that total industry supply and the spot market supply are decreasing in $\beta$, and so everything else being equal, in industries where contracted demand and spot market demand are positively correlated, industry supply and spot market supply are smaller. Because more supply will in general improve buyers' welfare, we see that negative demand correlation is good for buyers. This observation is consistent with results in previous work that show an increase in buyers' surplus when they use the two channels, contracts and spot markets, to manage risk.

\section{Discussion of Other Equilibriums}

Our analysis thus far has focused on situations in which the ILE exists. Clearly, this will not always be the case. If spot market prices are high enough to outweigh the penalty of not serving contracted demand then $q_{1}$ could be larger than $\left[Q_{1}-D\right]^{+}$; i.e., Supplier 1 may not be loyal to his contracting customers. This outcome is possible with either positive or negative demand correlation. Market transparency greatly expands the number of equilibriums that must be considered because we must account for the different ways in which $q_{2}$ could deviate from $Q_{2}$. An online appendix discussing the other equilibriums presented in Table 2 is available from the authors. Here, we briefly compare the AIE with the ILE to better understand the impact of market transparency.

\subsection{Example of Market Transparency Effect}

In Figures 4-7 we consider an example in which the ILE holds, for some range of $B$ values, when the market is not transparent, but with transparency the AIE holds and $q_{2}(H)<Q_{2}$. We compare the production quantities, spot market quantities, and profits for both suppliers as a function of $B$. We can see that the alternative interactive equilibrium holds for a wider range

Figure 4 Equilibrium Production Quantities as a Function of $B$

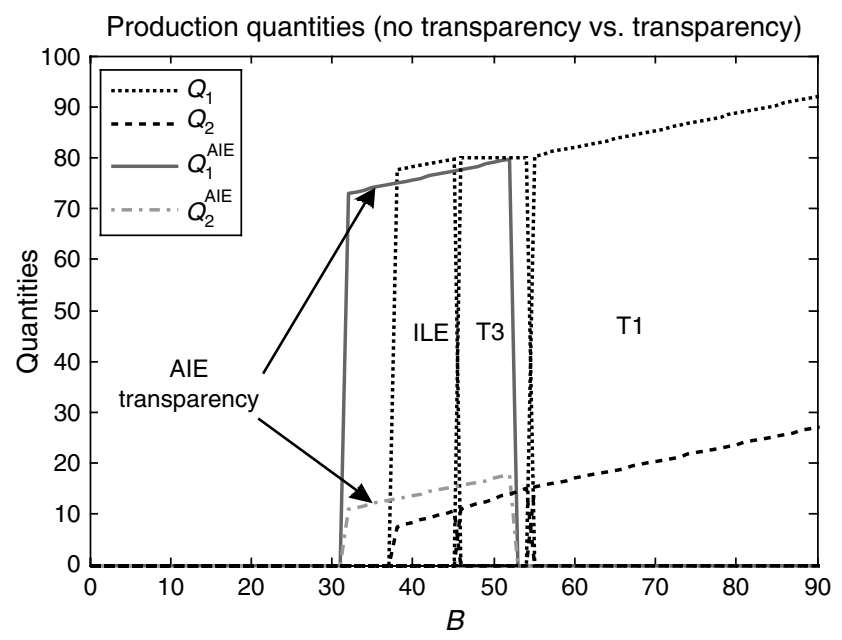

Note. $C=9, w=11, k=2, L=50, H=80, \beta=-2, s=1, \alpha=0.5$. 
Figure $5 \quad$ Equilibrium Profits as a Function of $B$

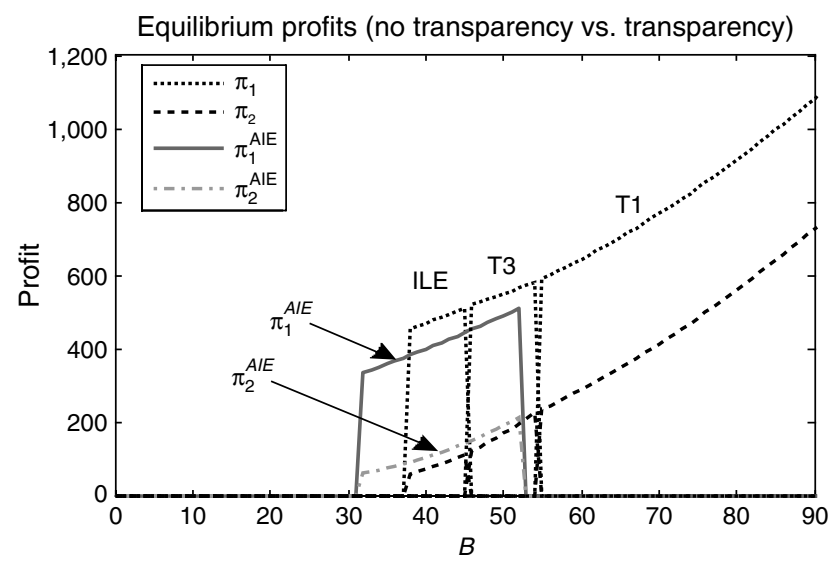

Note. $C=9, w=11, k=2, L=50, H=80, \beta=-2, s=1, \alpha=0.5$.

of $B$ values than the ILE. Comparing transparent markets with nontransparent markets, one would expect to see that Supplier 2 is better off in the latter type. In transparent markets Supplier 2 has more information and might choose to sell less than produced on the spot market. With this flexibility, we expect Supplier 2 to get more value out of each unit produced and therefore to produce more. We, in fact, see that $Q_{2}^{\mathrm{AIE}} \geq Q_{2}^{\mathrm{ILE}}$ (Figure 4) and $\pi_{2}^{\mathrm{AIE}} \geq \pi_{2}^{\mathrm{ILE}}$ (Figure 5). The additional flexibility for Supplier 2 is apparent in Figure 6 by observing that $q_{2}^{\mathrm{ILE}}(H) \geq q_{2}^{\mathrm{AIE}}(H)$. Similarly, we see that Supplier 1 is worse off with reduced profit (Figure 5) and smaller production (Figure 4) and spot market quantities (Figure 7).

\section{Conclusions}

To the best of our knowledge this is the first attempt to model a spot market with two types of suppliers: a supplier who faces contracted demand with fixed unit price, and a supplier who works solely on the spot market. Advances in communication networks

Figure $6 \quad q_{2}(H)$ as a Function of $B$

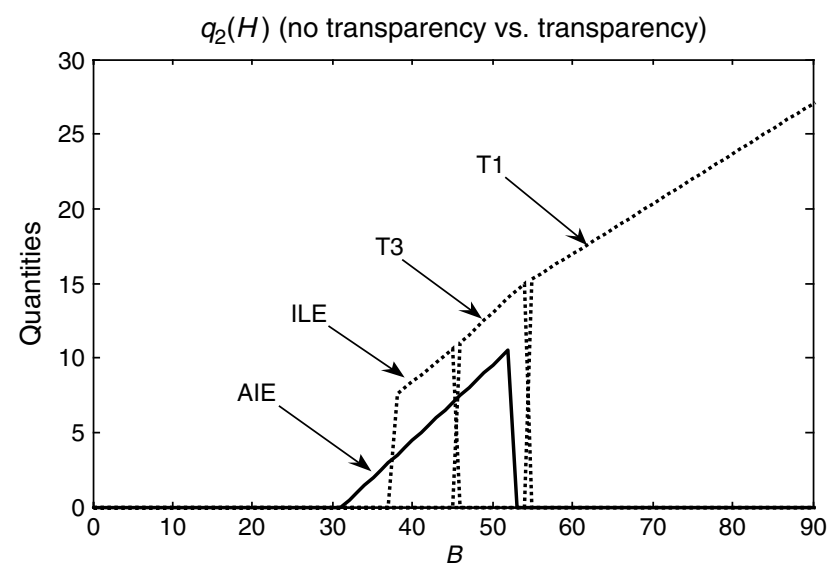

Note. $C=9, w=11, k=2, L=50, H=80, \beta=-2, s=1, \alpha=0.5$.
Figure $7 \quad q_{1}(L)$ as a Function of $B$

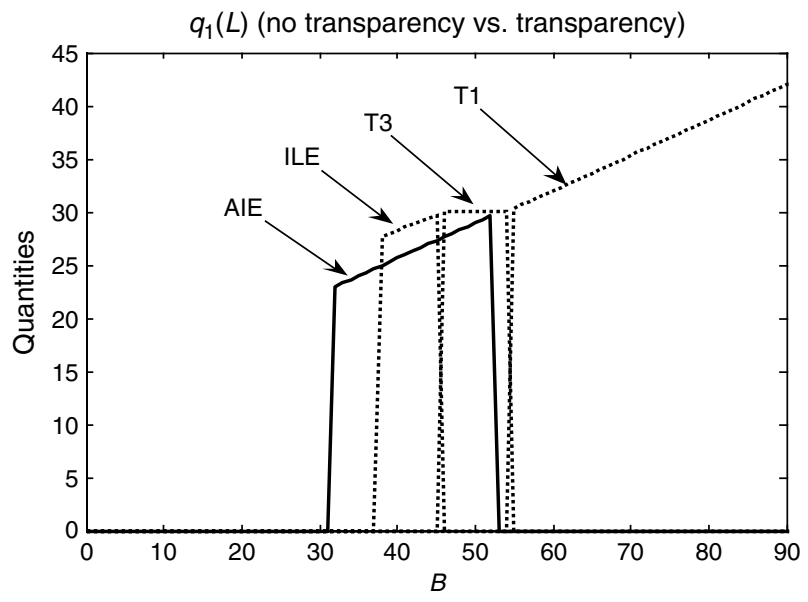

Note. $C=9, w=11, k=2, L=50, H=80, \beta=-2, s=1, \alpha=0.5$.

and the widespread use of the Internet have enabled new online spot markets to proliferate in industries that used to be dominated by forward contracting. Hence, suppliers that have forward contracts face new managerial decisions: Should they invest in a new spot market? Would they be better off as spot market's demand increases, given that other suppliers work solely on the spot market? Under which conditions should they give priority to contracted demand, rather than sell their inventory on the spot market? Our research provides guidelines and answers to these questions.

In this paper we focus on one equilibrium in which the supplier with contracts sells his entire excess inventory on the spot market when contracted demand is low and does not participate in the spot market when contracted demand is high. This equilibrium matches popular practice in industry: Suppliers with contracts give priority to demand originating from their contracts and use spot markets only to liquidate excess inventory. The main reason for the prevalence of this practice might be the limited liquidity in spot markets.

The existence of spot markets enables suppliers who have forward contracts to salvage excess inventory, reducing the cost of overestimating demand from their loyal customers. Hence, having access to the spot market clearly benefits these suppliers. In fact, we show that in the equilibrium described above, suppliers who have contracts not only increase their profits due to the spot market, but they benefit from it more than those suppliers who work solely on the spot market. In addition, when the spot market is small, the supplier that has contracts has a higher incentive to invest in expanding the spot market. When the spot market exceeds a threshold size, this situation is reversed, and the supplier with no contracts benefits more from making the spot market 
more prevalent. We also show that when spot market demand and contracted demand are independent or positively correlated, the supplier who works solely on the spot market would be better off if the other supplier eliminates contracting; i.e., he prefers to compete with suppliers who work solely on the spot market. At the same time we show that the existence of the spot market can make contracting profitable when otherwise it would be unprofitable.

Our model allows for either positive or negative correlation between contracted demand and spot market demand. We show that total industry supply and spot market supply are higher with negative correlation and that both buyer firms and suppliers that have forward contracts can benefit from negative correlation. However, suppliers that work only on the spot market would be better off working in industries where contracted demand and spot market demand are positively correlated.

One limitation of our model is using the Bernoulli distribution for contracted demand. Future work can examine the validity of our results with different distributions. Other extensions could examine suppliers with differing production costs or multiple suppliers from each type. In this paper we focus most of our attention on the interactive liquidation equilibrium. A more detailed analysis of other equilibriums, such as those in which the supplier with contracts can satisfy high contracted demand, or sells units on the spot market before satisfying contracted demand, would complement this work. One conclusion of this paper is that there are many possible equilibriums in spot markets with heterogeneous participants. As a result, predictions about their success, failure, or prevalence should be made cautiously.

\section{References}

Agrawal, N., S. Nahmias. 1997. Rationalization of the supplier base in the presence of yield uncertainty. Production Oper. Management 6(3) 291-308.

Agrawal, N., S. A. Smith, A. A. Tsay. 2002. Multi-vendor sourcing in a retail supply chain. Production Oper. Management 11(2) 157-182.
Araman, V., O. Ozer. 2003. Capacitated inventory management in the presence of a spot market. Working paper, Stanford University, Stanford, CA.

Araman, V., J. Kleinknecht, R. Akella. 2001. Supplier and procurement risk management: Optimal long-term and spot market mix. Working paper, Management Sciences and Engineering Department, Stanford University, Stanford, CA.

Caldentey, R., L. M. Wein. 2006. Revenue management of a maketo-stock queue. Oper. Res. 54(5) 859-875.

Deng, S., C. A. Yano. 2002a. Combining spot purchases with contracts in a two-echelon supply chain. Proc. MSOM Conf., Cornell University, Ithaca, NY.

Deng, S., C. A. Yano. 2002b. On the role of a second purchase opportunity in a two-echelon supply chain. Working paper, Department of Industrial Engineering and Operations Research, University of California Berkeley, Berkeley, CA.

Economist, The (UK). 2004. Survey: A market too far. (May 13) 514.

Greene, W. H. 2008. Econometric Analysis, 6th ed. Prentice Hall, Upper Saddle River, NJ.

Kouvelis, P., C. Chambers, H. Wang. 2006. Supply chain management research and production and operations management: Review, trends, and opportunities. Production Oper. Management 15(3) 449-469.

Lee, H., S. Whang. 2002. The impact of a secondary market on the supply chain. Management Sci. 48(6) 719-731.

Milner, J. M., P. Kouvelis. 2006. Inventory, speculation and sourcing strategies in the presence of online exchanges. Manufacturing Service Oper. Management. Forthcoming.

Peleg, B., H. L. Lee, W. H. Hausman. 2002. Short-term e-procurement strategies versus long-term contracts. Production Oper. Management 11(4) 458-479.

Seifert, R. W., U. W. Thonemann, H. H. Warren. 2004. Optimal procurement strategies for online spot markets. Eur. J. Oper. Res. 152(3) 781-799.

Sethi, S. P., H. Yan, H. Zhang. 2004. Quantity flexible contracts: Optimal decisions with information updates. Decision Sci. 35(2) 691-712.

Tunca, T. 2002. Essays on technology and information in financial and industrial exchanges. Ph.D. thesis, Stanford University, Stanford, CA.

$\mathrm{Wu}, \mathrm{D}$. J., P. R. Kleindorfer. 2003. Competitive options, supply contracting, and electronic markets. Management Sci. 51(3) 452-466.

$\mathrm{Wu}, \mathrm{D}$. J., P. R. Kleindorfer, J. E. Zhang. 2001. Integrating contracting and spot procurement with capacity options. Working paper, Department of Management, LeBow College of Business, Drexel University, Philadelphia.

Wu, D. J., P. R. Kleindorfer, J. E. Zhang. 2002. Optimal bidding and contracting strategies for capital-intensive goods. Eur. J. Oper. Res. 137(3) 657-676.

Yan, H., K. Liu, A. Hsu. 2003. Optimal ordering in a dual-supplier system with demand forecast updates. Production Oper. Management 6(3) 30-45. 